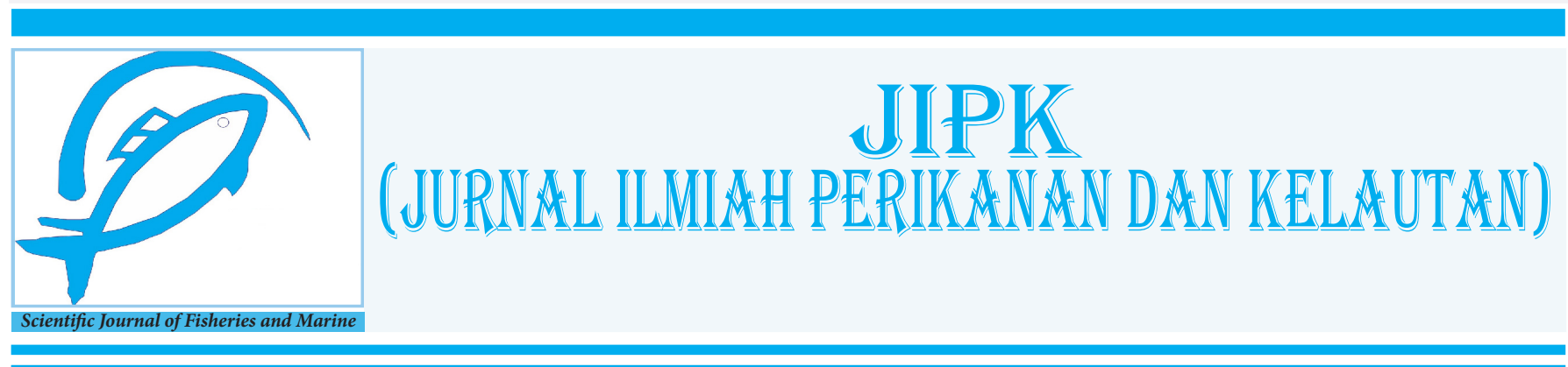

Research Article

\title{
Optimization of Medium Composition for Streptomyces sp. PB2 Chitinase Production using Response Surface Methodology
}

\author{
Anandita Perwita Kurniawan, Indun Dewi Puspita* (D), and Amir Husni \\ Department of Fisheries, Faculty of Agriculture, Universitas Gadjah Mada, Yogyakarta, 55281. Indonesia
}

\section{OPEN ACCESS}

\section{$\underline{\text { ARTICLE INFO }}$}

Received: June 18, 2021

Accepted: October 11, 2021

Published: October 16, 2021

*) Corresponding author:

E-mail: indun_dp@ugm.ac.id

Keywords:

Chitinase

$\mathrm{N}$-acetylglucosamine

Response Surface Method

Streptomyces sp.

PB2

This is an open access article under the CC BY-NC-SA license (https://creativecommons.org/ licenses/by-nc-sa/4.0/)

\begin{abstract}
Chitin is a polysaccharide compound composed of N-acetylglucosamine (NAG), which is linked by $\beta-1,4$-glycoside bonds. In producing NAG from chitin, enzymatic method using chitinase offer advantages compared to chemical degradation. Streptomyces sp. PB2 is a good candidate of chitinase producer which was previously isolated from shrimp pond sediment. However, optimization of chitinase production by Streptomyces sp. PB2 is required for large-scale production of this enzyme. This study aimed to find the optimal medium composition to increase the chitinase enzyme activity of Streptomyces sp. PB2 using the Response Surface Method. Initial screening was done to determine additional carbon and nitrogen sources in colloidal chitin broth suitable for increasing chitinase activity. Optimization of the medium composition was conducted using the PlackettBurman design to determine the critical components in the colloidal chitin broth medium and continued by Box-Behnken model to optimize the concentration of the medium components. Chitinase activity was obtained by measuring the amount of reducing sugar (NAG) released from enzymatic reaction using DMAB reagent by means of spectrophotometer. The medium components showing high contribution in increasing chitinase activity were $\mathrm{K}_{2} \mathrm{HPO}_{4}$, colloidal chitin and peptone, with the confidence level value of $0.66,0.48$, and 0.38 , respectively. The Box-Behnken model analysis shows that the combination of $\mathrm{K}_{2} \mathrm{HPO}_{4} 0.007 \mathrm{~g} /$ $\mathrm{ml}$, colloidal chitin $1.5 \mathrm{~g} / \mathrm{ml}$ and peptone $1.5 \mathrm{~g} / \mathrm{ml}$ in colloidal chitin broth are the optimal medium for Streptomyces sp. PB2, resulted in chitinase activity of 0.0125 $\mathrm{U} / \mathrm{ml}$. The increase of 6-fold in chitinase activity was achieved in this study.
\end{abstract}

Cite this as: Kurniawan, A. P., Puspita, I. D., \& Husni, A. (2022). Optimization of Medium Composition for Streptomyces sp. PB2 Chitinase Production using Response Surface Methodology. Jurnal Ilmiah Perikanan dan Kelautan, 14(1):1-11. http://doi. org/10.20473/jipk.v14i1.27602 


\section{Introduction}

Chitin is an unbranched compound composed of $\mathrm{N}$-acetylglucosamine (NAG) chains linked by $\beta$-1,4-glycoside bonds, insoluble in water and alcohol, insoluble in almost all organic solvents, and have hydrophobic properties (Gao et al., 2018). Chitin can be utilized as the main ingredient in the synthesis of NAG and oligomeric chitin. NAG is reported as a precursor for the biosynthesis of several macromolecules, such as glycolipids, glycoproteins, glucosaminoglycans (mucopolysaccharides), and proteoglycans in the body so that NAG can be applied in the medical field (Tork et al., 2018). Moreover, oligomeric chitin have bioactivity as antimicrobials, immune-enhancers and can activate the body's immune system (Karthik et al., 2015).

Chitinase plays an important role in the production of NAG by means of hydrolysis. Enzymatic hydrolysis is considered as an environmentally friendly method, economical, and easily managed (Karthik et al., 2015). Chitinase can be obtained from the metabolism of chitinolytic microorganisms (Meriem and Mahmoud, 2017). Chitinolytic microorganisms are commonly detected in environments with abundant sources of chitin such as hot water spring (Tuntun and Huda, 2014), sediments (Yahiaoui et al., 2019), and shell waste (Tarafdar and Biswas, 2013). Streptomyces $\mathrm{sp}$. is a group of chitinolytic bacteria from the genus Actinomycetes which is reported to be the best chitinase producer with a high chitinolytic index (Shivalee et al., 2018).

Previously, Streptomyces sp. PB2 was isolated from the mud of shrimp ponds in Yogyakarta with a chitinolytic activity of $0.0007 \mathrm{U} / \mathrm{ml}$ (Triwijayani et al., 2018). This isolate was similar to $S$. misionensis strain OsiRt-1 (99\%) based on partial 16S rRNA gene analysis, however $S$. misionensis OsiRt-1 shows negative result in chitinase production (Wang et al., 2016). To increase its chitinase activity, Kusumawijaya (2018) and Pramesti and Puspita (2020) have optimized the medium $\mathrm{pH}$, incubation temperature, colloidal chitin concentration, and inoculum concentration. The 2-fold increase in chitinase activity $(0.0018 \mathrm{U} / \mathrm{ml})$ compared to the initial chitinase activity was obtained from the optimization process, but this result was still relatively small. Thiagarajan et al. (2011) reported that Streptomyces sp. had a chitinolytic activity of $16.53 \mathrm{U} /$ $\mathrm{ml}$, whereas Jha et al. (2016) stated that $S$. rubiginosus was isolated from the rhizosphere of Gossypium sp. has a chitinase activity of $2.790 \mathrm{U} / \mathrm{ml}$.

The increase of chitinase activity can be obtain by optimizing the medium composition to meet the nutritional needs in the growth of chitinolytic bacteria
(Cheba et al., 2018). Increases in chitinase activity of Streptomyces sp. after optimization of the growth medium were demonstrated by Han et al. (2008) and by Meriem and Mahmoud (2017). However, Streptomyces harbored multiplicity of carbohydrate and protein degrading pathway. Variety of regulators related to nutrient utilization, such as MalR, Glk, GylR, CebR, GlcP, and DasR have been described for their implication in different physiological process in Streptomyces (Romero-Rodríguez et al., 2017). This variation implies the difference in growth medium requirement among Streptomyces. S. rubiginosus produces higher chitinase when supplemented with peptone compared to inorganic nitrogen sources (ammonium sulfate and ammonium nitrate) (Jha et al., 2016). Meanwhile, S. macrosporeus shows higher chitinase production when added with potassium nitrate compared to organic nitrogen sources (casein, peptone, malt extract, and yeast extract) (Sukalkar et al., 2018). The studies of medium optimization for chitinase production have been conducted in Streptomyces spp., but to our knowledge, very few studies have been reported in S. misionensis. Understanding the optimum growth medium among various species of Streptomyces provides useful information to formulate the common medium for this genus in producing chitinase.

This study aims to determine the optimal media composition to increase the production of chitinase from Streptomyces sp. PB2. In this study, Response Surface Methodology (RSM) was used to optimize the composition of the chitinase production medium of Streptomyces sp. PB2, because it offers an efficient experimental unit compare to factorial experimental design to analyse the effect and interaction between several factors.

\section{Materials and Methods}

\subsection{Preparation of Medium and Inoculum}

The medium for chitinase production was colloidal chitin broth consisting of $\mathrm{KH}_{2} \mathrm{PO}_{4}(0.03 \%)$ (Merck, Germany), $\mathrm{K}_{2} \mathrm{HPO}_{4} \quad(0.07 \%)$ (Merck, Germany), $\mathrm{MgSO}_{4} .5 \mathrm{H}_{2} \mathrm{O}(0.05 \%)$ (Merck, Germany), $\mathrm{ZnSO}_{4}(0.0001 \%)$ (Merck, Germany), $\mathrm{MnCl}_{2}(0.0001 \%)$ (Merck, Germany), and colloidal chitin (1.5\%) (Pramesti and Puspita, 2020). Colloidal chitin was prepared by mixing chitin from shrimp shell powder (Sigma, UK) with concentrated $\mathrm{HCl}$ according to Hsu and Lockwood (1975). The colloidal chitin broth and colloidal chitin agar were used for cell refreshment. Colloidal chitin agar was prepared following the colloidal chitin broth, with $1 \%$ Bacto Agar (Merck, Germany). Streptomyces sp. PB2 bacteria originating from laboratory collections 
in glycerol stock were refreshed by inoculation on chitin agar medium and incubating for 24 hours at $30^{\circ} \mathrm{C}$ to obtain working culture. Streptomyces sp. PB2 from working culture was inoculated on $7 \mathrm{ml}$ Nutrient Broth (Merck, Germany) and incubated for another two days at $37^{\circ} \mathrm{C}$. The culture was then centrifuged at 3000 rpm for 1 minute. The pellets were separated with the supernatant, then added with $1 \mathrm{ml}$ of sterile distilled water, vortexed, and the inoculum stock was obtained. Each procedure was carried out aseptically.

Tabel 1. Variables and Plackett-Burman Design levels

\begin{tabular}{|c|c|c|c|c|}
\hline \multirow{2}{*}{ Symbol } & \multirow{2}{*}{ Variables } & \multirow{2}{*}{ Units } & \multicolumn{2}{|c|}{ Experimental Levels } \\
\hline & & & -1 & 1 \\
\hline$\overline{X_{1}}$ & $\mathrm{KH}_{2} \mathrm{PO}_{4}$ & $\%$ & 0.003 & 0.008 \\
\hline $\mathrm{X}_{2}$ & $\mathrm{~K}_{2} \mathrm{HPO}_{4}$ & $\%$ & 0.007 & 0.014 \\
\hline$X_{3}$ & $\begin{array}{l}\text { Colloidal } \\
\text { Chitin }\end{array}$ & $\%$ & 1 & 2 \\
\hline $\mathrm{X}_{4}$ & Starch & $\%$ & 1 & 2 \\
\hline$X_{5}$ & Peptone & $\%$ & 0.5 & 1.5 \\
\hline
\end{tabular}

ammonium sulfate $\left(\left(\mathrm{NH}_{4}\right)_{2} \mathrm{SO}_{4}\right)$ (Merck, Germany), yeast extract (Merck, Germany), and peptone (Merck, Germany). One $\mathrm{ml}$ of inoculum was added to 100 $\mathrm{mL}$ of colloidal chitin broth supplemented with various additional carbon and nitrogen sources with a concentration of $1 \%$. The cultures were incubated in a reciprocal shaker at $125 \mathrm{rpm} 30^{\circ} \mathrm{C}$ for 3 days. Chitinase activity was observed at the end of incubation (day-3). The additional carbon and the nitrogen sources with the highest chitinase activity were chosen for optimization.

\subsection{Measurement of Chitinase Activity}

The chitinase activity test was carried out by taking $1 \mathrm{ml}$ of fermentation medium then centrifuged at $10,000 \mathrm{rpm}$ for 2 minutes at $4^{\circ} \mathrm{C}$ to obtain cell-free supernatant. The negative control was prepared by boiling $1 \mathrm{ml}$ of cell-free supernatant at $100^{\circ} \mathrm{C}$ for 3 minutes. Furthermore, $0.5 \mathrm{ml}$ of sample and 0.5 negative control were each reacted with $1 \mathrm{ml}$ of $1.3 \%$ colloidal chitin (in phosphate buffer $50 \mathrm{mM} \mathrm{pH} \mathrm{7.4)} \mathrm{and} \mathrm{incubated}$ for 30 minutes in a water bath shaker at $37^{\circ} \mathrm{C}$ with an agitation speed of $100 \mathrm{rpm}$. The mixture was then heated

Tabel 2. The Plackett-Burman Design Matrix and the resulting chitinase activity

\begin{tabular}{ccccccc}
\hline No. & $\mathbf{X}_{\mathbf{1}}$ & $\mathbf{X}_{\mathbf{2}}$ & $\mathbf{X}_{\mathbf{3}}$ & $\mathbf{X}_{\mathbf{4}}$ & $\mathbf{X}_{\mathbf{5}}$ & $\begin{array}{c}\text { Chitinase activity } \\
(\mathbf{U} / \mathbf{m l})\end{array}$ \\
\hline 1 & -1 & 1 & -1 & -1 & -1 & 0.002 \\
2 & -1 & 1 & 1 & -1 & 1 & 0.067 \\
3 & 1 & 1 & 1 & -1 & 1 & 0.004 \\
4 & -1 & -1 & -1 & -1 & -1 & 0.003 \\
5 & 1 & 1 & -1 & 1 & 1 & 0.000 \\
6 & 1 & -1 & 1 & -1 & -1 & 0.008 \\
7 & -1 & 1 & 1 & 1 & -1 & 0.000 \\
8 & -1 & -1 & -1 & 1 & 1 & 0.001 \\
9 & 1 & -1 & -1 & -1 & 1 & 0.001 \\
10 & -1 & -1 & 1 & 1 & 1 & 0.002 \\
11 & 1 & 1 & -1 & 1 & -1 & 0.005 \\
12 & 1 & -1 & 1 & 1 & -1 & 0.017 \\
\hline
\end{tabular}

\subsection{Selection of Additional Carbon and Nitrogen Source in the Fermentation Medium}

The selection aimed to determine the best additional carbon and nitrogen source in the colloidal chitin broth as a medium for chitinase production. The carbon sources were glucose (Merck, Germany), fructose (Merck, Germany), lactose (Merck, Germany), and starch (Merck, Germany). Nitrogen sources were potassium nitrate $\left(\mathrm{KNO}_{3}\right)$ (Merck, Germany), in water at $100^{\circ} \mathrm{C}$ for 3 minutes to stop the reaction, then cooled and centrifuged at $10,000 \mathrm{rpm}$ for 3 minutes (Liang, 2010). The amount of $\mathrm{N}$-acetylglucosamine (NAG) produced from the enzymatic reaction was measured according to Reissig et al. (1955). A total of $250 \mu 1$ of sample and control from enzymatic reaction were added with $50 \mu 1$ of potassium tetraborate (Wako, Japan) (pH 9.1) then boiled for 3 minutes to bind NAG. Furthermore, the sample was cooled and added with 
$1.25 \mathrm{ml}$ of DMAB (dimethyl amino benzaldehyde) (Merck, Germany) reagent and incubated at $37^{\circ} \mathrm{C}$ for 20 minutes. Standard NAG (TCI, Japan) solutions at various concentrations $(0,10,20,30,40$, and $50 \mu \mathrm{g} / \mathrm{ml})$ were used to construct standard curves. The absorbance of the sample and the standard solution was measured with a UV-Vis spectrophotometer (Thermo Scientific, US) at a wavelength of $585 \mathrm{~nm}$. The NAG concentration was obtained by comparing the absorbance value of the sample with the absorbance value of the standard NAG curve. One unit of chitinase enzyme activity was defined as the amount of NAG ( $\mu$ mol) released per minute in the enzymatic reaction under the conditions mentioned above.

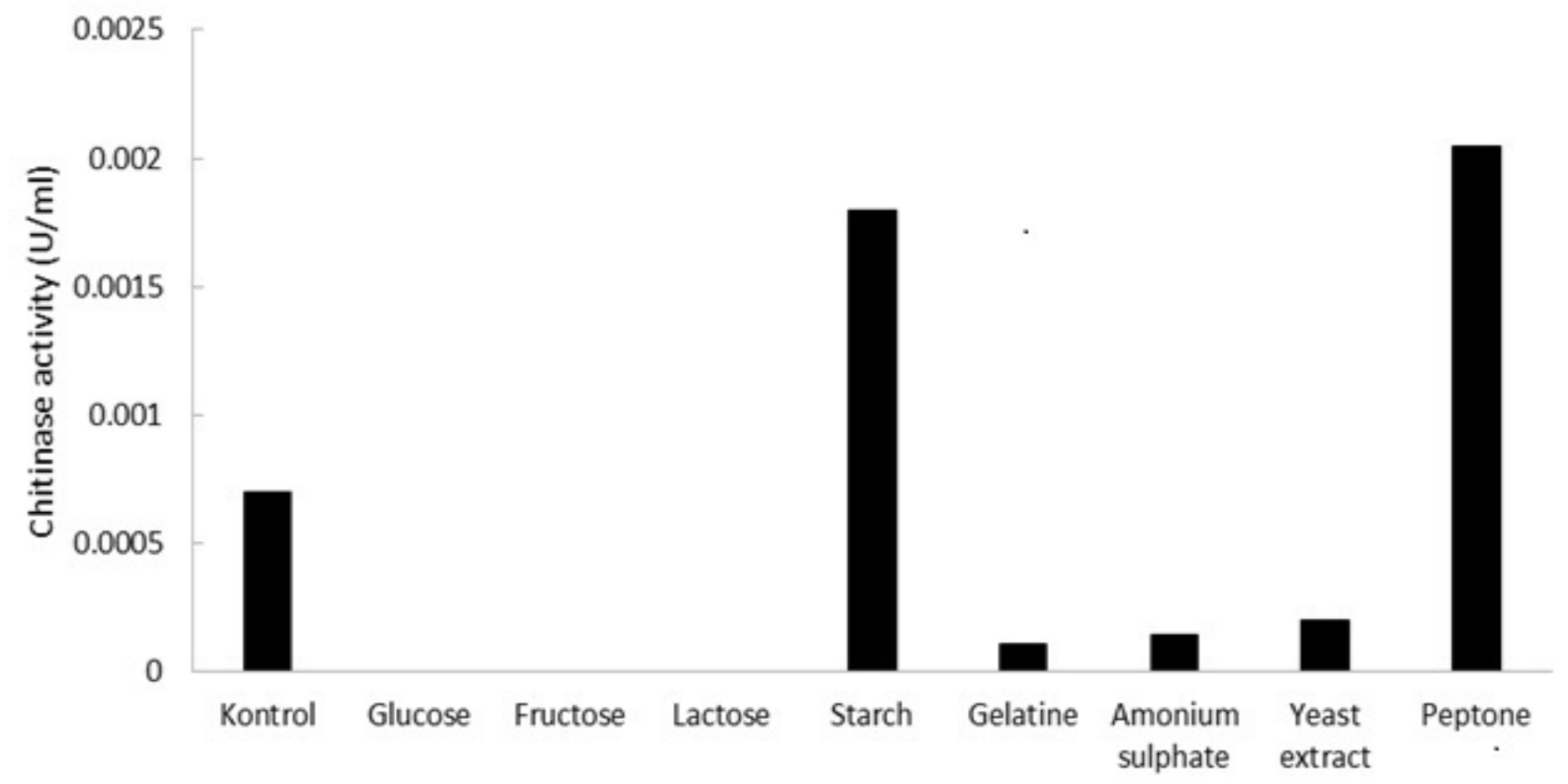

Figure 1. Chitinase activity $(\mathrm{U} / \mathrm{ml})$ of Streptomyces sp. $\mathrm{PB} 2$ on colloidal chitin broth $\left(30^{\circ} \mathrm{C}, 125 \mathrm{rpm}, 3\right.$ days $)$ with the addition of various types of carbon and nitrogen sources (1\%)

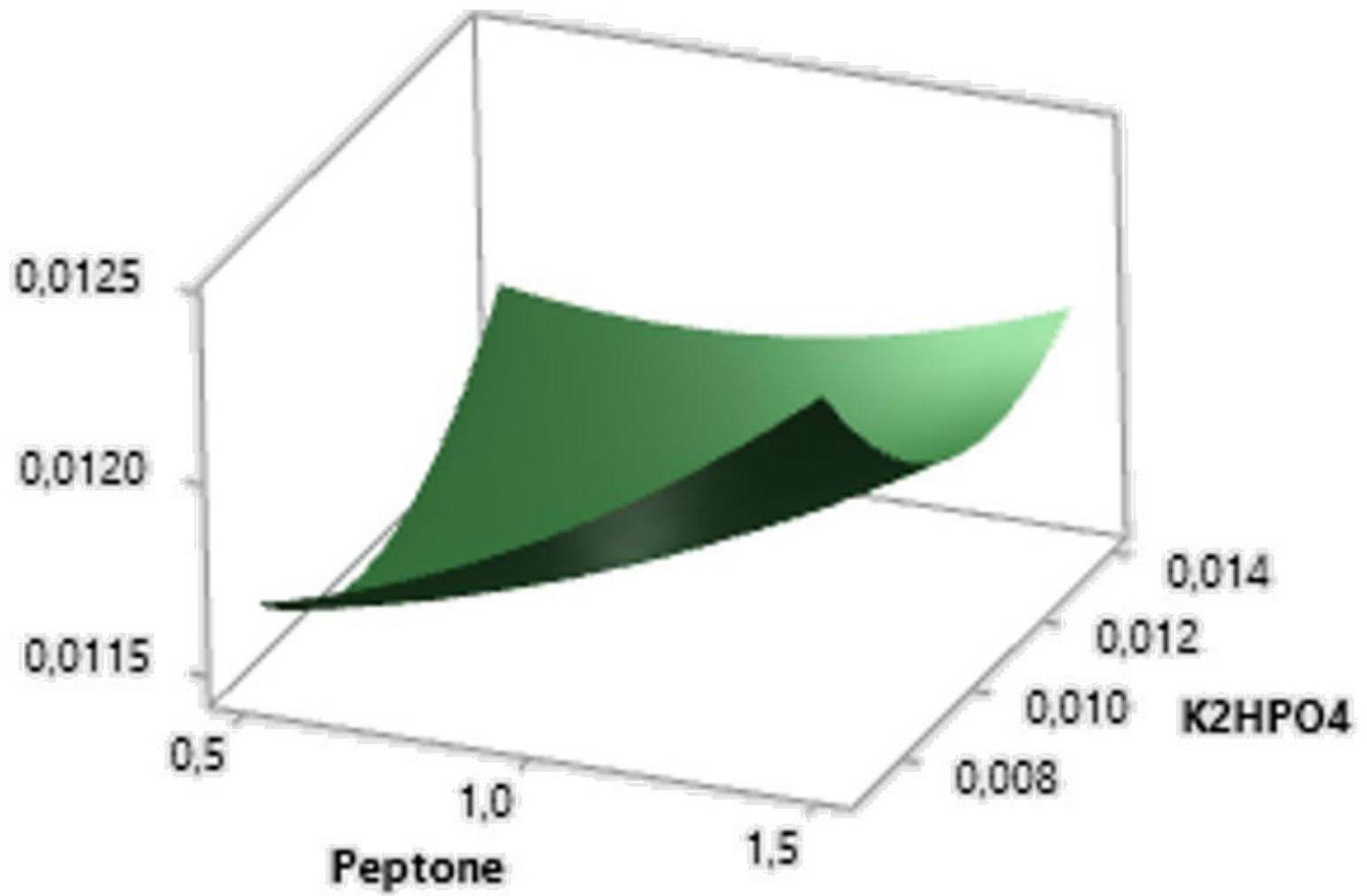

Figure 2. 3-dimensional graph of the effect of peptone and K2HPO4 on chitinase activity

4 Jurnal Ilmiah Perikanan dan Kelautan 
JIPK. Volume 14 No 1. April 2022 / Optimization of Medium Composition for Streptomyces sp. PB2 Chitinase...

\subsection{Optimization of Medium Composition by Using a Statistical Design Approach}

Streptomyces sp. PB2 was fermented in colloidal chitin broth with various treatment combinations of medium components. The inoculum concentration of $1.5 \%$ in $100 \mathrm{ml}$ colloidal chitin broth was used in the fermentation process. Fermentation was carried out in a reciprocal shaker at $30^{\circ} \mathrm{C} 125 \mathrm{rpm}$ for 3 days and chitinase activity was analysed.

Optimization of the medium composition was conducted in two stages. The first stage was carried out using the Plackett-Burman design (PBD) to determine the critical components in the colloidal chitin broth medium that affect Streptomyces sp. PB2 chitinase. PBD is a two-factorial analysis design that allows selecting the number of variables in $\mathrm{n}+1$ experiments (Plackett and Burman, 1946). Five of the total eight components of the medium were selected for the screening stage using two concentration levels for each component, namely high (+1) and low (-1) (Table 1). The medium components that were not included in the screening stage and had a constant concentration in each treatment were $\mathrm{MgSO}_{4} .5 \mathrm{H}_{2} \mathrm{O}(0.05 \%), \mathrm{ZnSO}_{4}(0.0001 \%)$, and $\mathrm{MnCl}_{2}(0.0001 \%)$.

The experimental matrix design of variables (medium components) and levels (medium concentration) combination was created with Minitab 19 (Table 2). The formula used to determine the effect of each component of the medium is:

$$
Y=\beta_{0}+\Sigma \beta_{i} X_{i}+\varepsilon
$$

After the critical medium components in increasing chitinase activity were identified, the next step was to optimize the concentration of the medium components using the Response Surface Method (RSM) Box-Behnken model (Box and Draper, 2007). The selected medium component variables were examined using three different concentration levels: codes -1 , 0 , and +1 (Table 4). The matrix design of parameters and levels combination, including the centre point experiment, was created by using Minitab 19 software (Table 5).

The following second-order polynomial equations were used to predict optimal chitinase production:

$$
Y=\beta_{0}+\Sigma \beta_{i} X_{i}+\Sigma \beta_{i j} X_{i} X_{j}+\Sigma \beta_{i i} X_{i}^{2}
$$

where:

$$
\begin{array}{ll}
\mathrm{Y} & : \text { response to chitinase activity } \\
\beta_{0} & : \text { initial equation, } \\
\beta_{i} & : \text { linear equation, } \\
\beta_{i i} & : \text { quadratic equation, and } \\
\beta_{i j} & : \text { interaction equation value }
\end{array}
$$

The most optimal prediction results were compared with the observation results to determine the model's validity. Root Mean Squared Error (RMSE) was calculated to measure the standard deviation of the residuals. Data were analyzed with Minitab 19 software.

\section{Results and Discussion}

The production of bacterial chitinase is influenced by growth factors, such as medium component. Han et al. (2008) found that the maximum chitinase activity and the cell growth (dry weight) of Streptomyces sp. DA11 increase 39.2 and 2.6- fold higher in statistically optimized medium compared to basic medium. The production curve of chitinase showed a similar pattern with the growth curve and both reached the highest peak in $72 \mathrm{~h}$ of incubation. Our previous study also showed that Streptomyces sp. PB2 reached the maximum chitinase activity in $48 \mathrm{~h}$ at the same time of bacterial growth reach the late logarithmic phase (Pramesti and Puspita, 2020). It indicates that chitinase is a primary metabolite. Moreover, the production of bacterial primary metabolite such as enzyme is regulated by several positive and negative mechanisms, including induction and nutritional regulation (carbon and nitrogen source regulation) (Sanchez and Demain, 2008). Therefore, increase in enzyme production can be achieved by optimizing bacterial growth condition including medium component.

\subsection{Selection of Additional Carbon and Nitrogen Sources}

The utilization of sugar compound in the medium for growth and other metabolic activity depends on the suitability of the carbon source to bacterial preferences (Bruckner and Titgemeyer, 2002). Starch is an additional carbon source that could increase chitinase activity with the highest value of $0.0018 \mathrm{U} / \mathrm{ml}$ (Figure 1). Ray (2018) also reports that starch is the best source of carbon substrates for S. chilikensis RC1830. 
Table 3. Effect of the Plackett-Burman design on chitinase activity

\begin{tabular}{llccccc}
\hline \multicolumn{1}{c}{ Factors } & \multicolumn{1}{c}{$\begin{array}{c}\text { Medium } \\
\text { Components }\end{array}$} & Effects & S.E. & T-Value & P-Value & $\begin{array}{c}\text { Confidence } \\
(\%)\end{array}$ \\
\cline { 2 - 6 } $\mathrm{X}_{1}$ & $\mathrm{KH}_{2} \mathrm{PO}_{4}$ & -0.010 & 0.006 & -0.83 & 0.436 & -0.5 \\
$\mathrm{X}_{2}$ & $\mathrm{~K}_{2} \mathrm{HPO}_{2}$ & 0.013 & 0.006 & 1.1 & 0.315 & 0.66 \\
$\mathrm{X}_{3}$ & Colloidal chitin & 0.010 & 0.006 & 0.8 & 0.454 & 0.48 \\
$\mathrm{X}_{4}$ & Starch & -0.005 & 0.006 & -0.45 & 0.671 & -0.27 \\
$\mathrm{X}_{5}$ & Peptone & 0.008 & 0.006 & 0.63 & 0.55 & 0.38 \\
\hline
\end{tabular}

Table 4. Levels and concentrations of variables in Box-Behnken

\begin{tabular}{|c|c|c|c|c|c|}
\hline \multirow{2}{*}{ Symbol } & \multirow{2}{*}{ Variables } & \multirow{2}{*}{ Unit } & \multicolumn{3}{|c|}{ Levels } \\
\hline & & & -1 & $\mathbf{0}$ & 1 \\
\hline $\mathrm{X}_{2}$ & $\mathrm{~K}_{2} \mathrm{HPO}_{4}$ & $\%$ & 0.007 & 0.01 & 0.014 \\
\hline$X_{3}$ & Colloidal chitin & $\%$ & 1 & 1.5 & 2 \\
\hline$X_{5}$ & Peptone & $\%$ & 0.5 & 1 & 1.5 \\
\hline
\end{tabular}

Table 5. Box-Behnken experimental design and chitinase activity observed

\begin{tabular}{|c|c|c|c|c|}
\hline \multirow{2}{*}{ Run } & \multicolumn{3}{|c|}{ Levels } & \multirow{2}{*}{ Chitinase Activity (U/ml) } \\
\hline & $X_{2}$ & $\mathbf{X}_{3}$ & $\mathbf{X}_{5}$ & \\
\hline 1 & 0 & -1 & 1 & 0.012 \\
\hline 2 & -1 & 1 & 0 & 0.012 \\
\hline 3 & 0 & 1 & -1 & 0.012 \\
\hline 4 & -1 & 0 & 1 & 0.013 \\
\hline 5 & 0 & 1 & 1 & 0.012 \\
\hline 6 & 1 & 1 & 0 & 0.012 \\
\hline 7 & 0 & -1 & -1 & 0.012 \\
\hline 8 & 1 & 0 & -1 & 0.012 \\
\hline 9 & -1 & -1 & 0 & 0.012 \\
\hline 10 & 1 & -1 & 0 & 0.012 \\
\hline 11 & -1 & 0 & -1 & 0.012 \\
\hline 12 & 1 & 0 & 1 & 0.012 \\
\hline 13 & 0 & 0 & 0 & 0.012 \\
\hline 14 & 0 & 0 & 0 & 0.012 \\
\hline 15 & 0 & 0 & 0 & 0.012 \\
\hline
\end{tabular}

Table 6. Validation of the mathematical model of chitinase activity in colloidal chitin broth with a concentration of $\mathrm{K}_{2} \mathrm{HPO}_{4} 0.007 \%$, colloidal chitin $1.5 \%$, and peptone $1.5 \%$

\begin{tabular}{|c|c|c|c|c|}
\hline \multicolumn{3}{|c|}{ Observed chitinase activity (U/ml) } & \multirow{2}{*}{$\begin{array}{l}\text {-Mean of observed chitinase } \\
\text { activity }(\mathrm{U} / \mathrm{ml})\end{array}$} & \multirow{2}{*}{$\begin{array}{l}\text { Calculated chitinase } \\
\text { activity }(\mathrm{U} / \mathrm{ml})\end{array}$} \\
\hline Replication 1 & Replication 2 & Replication 3 & & \\
\hline 0.013 & 0.012 & 0.013 & 0.013 & 0.012 \\
\hline
\end{tabular}


Chitinase activity in Streptomyces chilikensis RC1830 with the addition of $1 \%$ starch and $1 \%$ colloidal chitin was $2.24 \mathrm{U}$. Starch is categorized in the polysaccharide group composed of more than three simple sugar units with amylose and amylopectin as constituents (Bertoft, 2017). Starch with a concentration of $1 \%$ in colloidal chitin broth is estimated to be a link between the chitin substrate and the chitinase enzyme released by bacterial cells (Narayana and Vijayalakshmi, 2009).

Additional of starch in colloidal chitin broth is more suitable for Streptomyces sp. PB2 to produce chitinase than glucose, fructose, and lactose. In the case where there are two or more carbon sources in a medium, bacteria will choose the carbon source that require the most efficient energy through the Carbon Catabolite Repression (CCR) mechanism (Vinuselvi et al., 2012). Allegedly, the addition of glucose and other simple sugar molecules tend to cause repression of the chitinase enzyme. Enzyme repression occurs when a compound has a low molecular weight, either a product or a compound related to the reaction concerned, acts as a corepressor by preventing the synthesis of the enzyme (Pelczar and Chan, 1986).

Table 7. ANOVA and regression analysis for chitinase activity

\begin{tabular}{|c|c|c|c|c|c|}
\hline $\begin{array}{c}\text { Source of } \\
\text { Variant } \\
\end{array}$ & $\begin{array}{c}\text { Degree of } \\
\text { freedom }\end{array}$ & $\begin{array}{c}\text { Sum of } \\
\text { Squares }\end{array}$ & $\begin{array}{c}\text { Mean } \\
\text { square }\end{array}$ & F-Value & P-Value \\
\hline Model & 9 & 0,000 & 0 & 5.73 & 0.034 \\
\hline Square & 3 & 0 & 0 & 5.89 & 0.043 \\
\hline$X_{2}$ & 1 & 0 & 0 & 16.14 & 0.01 \\
\hline$X_{3}$ & 1 & 0 & 0 & 0 & 0.955 \\
\hline$X_{5}$ & 1 & 0 & 0 & 2.25 & 0.194 \\
\hline Error & 5 & 0 & 0 & & \\
\hline Lack of Fit & 3 & 0 & 0 & 0.02 & 0.995 \\
\hline Pure Error & 2 & 0 & 0 & & \\
\hline
\end{tabular}

Table 8. R-Square Test Model

\begin{tabular}{cccc}
\hline S & R-sq & $\begin{array}{c}\text { R-sq } \\
\text { (adj) }\end{array}$ & $\begin{array}{c}\text { R-sq } \\
\text { (pred) }\end{array}$ \\
\hline 0.000 & $91.17 \%$ & $75.26 \%$ & $76.72 \%$ \\
\hline
\end{tabular}

As with carbon sources, the growth of chitinolytic bacteria and the metabolic activity of bacteria are also influenced by the type of nitrogen sources. Nitrogen is an essential factor in cell metabolism because it affects enzyme synthesis, both in the formation of primary and secondary metabolites. Moreover, bacteria also need nitrogen for protein and amino acids synthesis in the growth phase (Chakrabortty et al., 2012). Nitrogen sources can decrease or increase chitinase activity, depending on the suitability of the number and preference of bacteria (Xia et al., 2011). Peptone is a source of additional nitrogen that produces the highest chitinase activity in Streptomyces sp. PB2, which is $0.0020 \mathrm{U} / \mathrm{ml}$ (Figure 1). Pepton is known to be a suitable nitrogen source to increase chitinase activity in Streptomyces sp. compared to other nitrogen substrate sources (Beef extract, $\mathrm{MgSO}_{4}$, Dihydrogen potassium phosphate) with chitinase activity of $4.28 \mathrm{U} / \mathrm{ml}$ (Jha et al., 2016). Pepton is a source of nitrogen that is often used as a macronutrient by various microorganisms. Further optimization was performed using starch and peptone with the Plackett-Burman design optimization model.

\subsection{Screening the Essential Components of the Medium}

The screening of essential components in the medium that can increase chitinase activity was carried out using the Plackett-Burman design (PBD) statistical method. PBD is a suitable method and is widely used in the selection of medium compositions. PBD can also be used for significant variables screening (Box and Draper, 2007). The medium components (starch and peptone) selected from the initial stage, together with medium components of colloidal chitin broth $\left(\mathrm{KH}_{2} \mathrm{PO}_{4}, \mathrm{~K}_{2} \mathrm{HPO}_{4}\right.$, and colloidal chitin) were optimized to increase the chitinase activity of Streptomyces sp. PB2. The highest chitinase activity of $0.067 \mathrm{U} / \mathrm{ml}$ was achieved with high levels $(+1)$ of $\mathrm{K}_{2} \mathrm{HPO}_{4}\left(\mathrm{X}_{2}\right)$, colloidal chitin $\left(\mathrm{X}_{3}\right)$, and peptone $\left(\mathrm{X}_{5}\right)$ combination (Table 2$)$.

The statistic parameters (standard error, T-value, $\mathrm{P}$-value, and confidence percentage) were analysed to determine the effect of substrate addition on chitinase activity. The highest confidence level value showed that the medium component had the highest contribution in increasing chitinase activity (Han et al., 2008). $\mathrm{K}_{2} \mathrm{HPO}_{4}$ had the highest confidence level, followed by colloidal chitin and peptone (Table 3). The three components of this medium were continued for further optimization using Response Surface Method (RSM).

$\mathrm{K}_{2} \mathrm{HPO}_{4}$ affects the increase in cell density of microorganisms (Meriem and Mahmoud, 2017) through a buffer reaction mechanism in controlling the $\mathrm{pH}$ value so that bacterial growth runs faster (Hayek and Ibrahim, 2013). Meanwhile, Saima et al. (2013) reported that colloidal chitin is the most suitable substrate for increasing chitinase activity and cell growth. Colloidal chitin is a carbon source that also acts as an inducer for chitinase synthesis. Colloidal chitin from shrimp shells is reported to be easily absorbed and utilized as nutrients in some microbes (Brzezinska et al., 2013). Peptone is 
a source of complex organic nitrogen, which can be hydrolyzed by proteases in Streptomyces sp., converted into several types of amino acids which are further used to synthesize chitinase and for cell growth (Shivalee et al., 2018).

\subsection{Media Component Optimization}

The three mostessential components in the media for increasing the chitinase activity of Streptomyces sp. PB2 was further optimized using Box-Behnken Design (BBD). BBD is one of the experimental designs in RSM. BBD is suitable for surface response optimization for three variables. This program can be used to analyze and model a problem with one or more treatments (Montgomery, 2001). The highest chitinase activity of $0.0125 \mathrm{U} / \mathrm{ml}$ was achieved by the combination of low level $\mathrm{K}_{2} \mathrm{HPO}_{4}\left(\mathrm{X}_{2}\right)$, middle level colloidal chitin $\left(\mathrm{X}_{3}\right)$, and high level peptone $\left(\mathrm{X}_{5}\right)$ (Table 5).

The data of observed chitinase activity values were analyzed by multiple linear regressions using Minitab 19. The mathematical equation obtained from the analysis to describe the relationship between variables $\left(\mathrm{X}_{2}, \mathrm{X}_{3}\right.$, and $\left.\mathrm{X}_{5}\right)$ and response $(\mathrm{Y})$ was based on the following equation.

$y=0.01228+0.000695 X_{5}+0.000678 X_{3}-0.323 X_{2}+0.000419 X_{5}^{2}+0.000017 X_{3}^{2}+22.89 X_{2}^{2}-$ $0.000100 X_{5} X_{3}-0.0861 X_{5} X_{2}-0.0574 X_{3} X_{2}$

Positive values for the coefficients of $\mathrm{X}_{3}$ and $\mathrm{X}_{5}$ indicate that chitinase activity increases with the increase in colloidal chitin and peptone concentrations in the medium. The interactions and influences between factors are shown in the surface plot (Figure 2), which forms a peak on the three-dimensional curve. The indentation on the surface plot can show the value of the optimum response (Meriem and Mahmoud, 2017). Based on mathematical model equations and surface plot response analysis, the optimal concentrations of $\mathrm{K}_{2} \mathrm{HPO}_{4}\left(\mathrm{X}_{2}\right)$, colloidal chitin $\left(\mathrm{X}_{3}\right)$, and peptone concentrations $\left(\mathrm{X}_{5}\right)$ to obtain maximum $\mathrm{Y}$ values were $0.007 \%, 1.5 \%$, and $1.5 \%$, respectively.

The chitinase activity obtained in this study was lower than other studies, such as in S. macrosporeus M1 (9.2 U/ml) (Sukalkar et al., 2018) and Streptomyces sp. DA11 (36.43 U.ml) (Han et al., 2008). Difference in source of microorganism and bacterial species may described the variation of chitinase production because they possibly have difference cellular metabolic pathway. Streptomycetes are well known as a soil dweller in which different region of soil might contain different level of insoluble polymers. Therefore, Streptomycetes harbored multiplicity of carbohydrate and protein degrading pathways which depends on the availability of nutrients in their natural habitats.
Difference in carbohydrate transport systems, CCR of intracellular and extracellular catabolic enzymes, proteolytic enzymes, metabolism pathway of amino acids and nucleotide have been reported in different Streptomycetes (Romero-Rodríguez et al., 2017).

\subsection{Experiment Validation}

Validation testing is carried out to determine the accuracy and correctness of a mathematical model with actual conditions. Validation testing was carried out on the optimal treatment with three replications. The result shows that the value of observed chitinase activity were similar to the results from the mathematical model calculations (Table 6). The calculated chitinase activity was $0.0124 \mathrm{U} / \mathrm{ml}$, meanwhile, the average of observed chitinase activity was $0.0125 \mathrm{U} / \mathrm{ml}$. This value indicates an accuracy of $100.8 \%$ compared to the predicted value. Calculation of RMSE shows the value of 0.00025 which indicated low deviations between the predicted and the actual values.

Furthermore, the model was validated by ANOVA and regression analysis using Minitab 19. The analysis included testing the ANOVA assumption and three statistical tests of model fit test (lack of fit test, sum of square test, and R-square test) (Table 7). The p-value was used to conclude the hypothesis of the model accuracy. There are two models, the linear model and the quadratic model. The mathematical model will appear in the variance source according to the order used. Order I uses linear models, and order II uses quadratic models. This study uses a quadratic model (order II) where significance is obtained if the $p$-value $<0.05$. The p-value for the quadratic model of 0.043 , so it can be concluded that the quadratic mathematical model is suitable for testing the chitinase enzyme activity in this study (Table 7). ANOVA analysis also indicates that there were no interactions ( $p$-value $>0.05$ ) between variables that were tested (data was not showed). The next stage is the lack of fit test to determine the fit between models, where a good model does not have a lack of fit. The p-value $>0.05$ was the hypothesis used to determine there was no lack of fit. The analysis showed that the p-value was 0.995 (Table 7), so it is concluded that there is no lack of fit in the model used. The relationship between the prediction model and the observed results were obtained from the R-square value (Table 8). The $\mathrm{R}$-square value was 0.91 . The best mathematical model has an R-square value close to 1 . The R-square value of 0.91 indicates that the results of chitinase activity are influenced by the peptone factor, colloidal chitin, and $\mathrm{K}_{2} \mathrm{HPO}_{4}$ with a probability of 0.91 .

This study implied that the combination of Starch $1 \%, \mathrm{KH}_{2} \mathrm{PO}_{4} 0.003 \%, \mathrm{~K}_{2} \mathrm{HPO}_{4} 0.007 \%$, colloidal 
chitin $1.5 \%$, and peptone $1.5 \%$ in colloidal chitin broth significantly increased chitinase activity of Streptomyces sp. PB2. Previously, Pramesti and Puspita (2020) optimized the colloidal chitin concentration in the medium and inoculum concentrations of Streptomyces sp. PB2 yielded chitinase activity of $0.0019 \mathrm{U} / \mathrm{ml}$. Optimization of the medium composition in this study increased chitinase activity to $0.0125 \mathrm{U} / \mathrm{ml}$. Nutritional optimization is required to achieve the best conditions for bacterial enzyme production.

\section{Conclusion}

This study revealed that medium optimization significantly improved Streptomyces sp. PB2 chitinase production with a 6-fold increase in activity. $\mathrm{K}_{2} \mathrm{HPO}_{4}$, colloidal chitin, and peptone are the important medium components in increasing chitinase production of Streptomyces sp. PB2. However, this study only considered chitinase activity as the sole parameter in achieving the optimized condition, whereas as the primary metabolite, the production of chitinase is related to bacterial growth. Therefore, the measurement of biomass production is strongly suggested to provide their comprehensive relationship in nature. Further analysis about the metabolic regulation using molecular biology approaches is required to understand its mechanism that is potentially useful for strain improvement.

\section{Acknowledgement}

We would like to thank Universitas Gadjah Mada for providing fund for this research.

\section{Authors' Contributions}

All authors have contributed to the final manuscript. The contribution of each author as follow, APK; collected the data, drafted the manuscript and designed the figures. IDP and AH; devised the main conceptual ideas and critical revision of the article. All authors discussed the results and contributed to the final manuscript.

\section{Conflict of Interest}

The authors declare that they have no competing interests

\section{Funding Information}

This work was supported by Universitas Gadjah Mada under the RTA 2019 Program (3258/UN1/ DITLIT/DIT-LIT/LT/2019).

\section{References}

Bertoft, E. (2017). Understanding starch structure: Recent progress. Agronomy, 7(56):1-29.

Box, G. E. P., \& Draper, N. E. (2007). Response surfaces, mixtures, and ridge analyses $\left(2^{\text {nd }} e d.\right)$. New Jersey: John wiley \& sons.

Bruckner, R., \& Titgemeyer, F. (2002). Carbon catabolite repression in bacteria: Choice of the carbon source and autoregulatory limitation of sugar utilization. FEMS Microbiology Letters, 209(2):141-148.

Brzezinska, M. S., Jankiewicz, U., \& Walczak, M. (2013). Biodegradation of chitinous substances and chitinase production by the soil actinomycete Streptomyces rimosus. International Biodeterioration \& Biodegradation, 84:104-110.

Chakrabortty, S., Bhattacharya, S., \& Das, A. (2012). Optimization of process parameters for chitinase production by a marine isolate of Serratia marcescens. International Journal of Pharmacy and Biological Sciences, 2(2):8-20.

Cheba, B. A., Zaghloul, T. I., El-Mahdy, A. R., \& ElMassry, M. H. (2018). Effect of nitrogen sources and fermentation conditions on bacillus sp. R2 chitinase production. Procedia Manufacturing, 22(2018):280-287.

Gao, L., Sun, J., Secundo, F., Gao, X., Xue, C., \& Mao, X. (2018). Cloning, characterization and substrate degradation mode of a novel chitinase from Streptomyces albolongus ATCC 27414. Food Chemistry, 261:329-336.

Han, Y., Li, Z., Miao, X., \& Zhang, F. (2008). Statistical optimization of medium components to improve the chitinase activity of Streptomyces sp. Da11 associated with the South China Sea sponge Craniella australiensis. Process Biochemistry, 43(10):1088-1093.

Hayek, S. A., \& Ibrahim, S. A. (2013). Current limitations and challenges with Lactic Acid Bacteria: A review. Food and Nutrition Sciences, 04(11):73-87.

Hsu, S. C., \& Lockwood, J. L. (1975). Powdered chitin agar as a selective medium for enumeration of Actinomycetes in water and soil. Applied and Environmental Microbiology, 29(3):422-426.

Jha, S., Modi, H. A., \& Jha, C. K. (2016). Characterization of extracellular chitinase produced from Streptomyces rubiginosus isolated from rhizosphere of Gossypium sp. Cogent Food 


\section{\& Agriculture, 2(1):1198225.}

Karthik, N., Binod, P., \& Pandey, A. (2015). Purification and characterisation of an acidic and antifungal chitinase produced by a Streptomyces sp. Bioresource Technology, 188:195-201.

Kusumawijaya, I. F. (2018). Optimasi Produksi Kitinase Streptomyces sp. PB-2 pada berbagai $\mathrm{pH}$ Medium dan Suhu Inkubasi. Thesis. Yogyakarta: Universitas Gadjah Mada.

Liang, T. W. (2010). Purification and characterization of chitinase from a new species strain Pseudomonas sp. TKU008. Journal of Microbiology and Biotechnology, 20(6):1001-1005.

Meriem, G., \& Mahmoud, K. (2017). Optimization of chitinase production by a new Streptomyces griseorubens C9 isolate using response surface methodology. Annals of Microbiology, 67(2):175183.

Montgomery, D. C. (2001). Design and analysis of experiments $\left(5^{\text {th }}\right.$ ed.). New Jersey: John Wiley \& Sons.

Narayana, K. J. P., \& Vijayalakshmi, M. (2009). Chitinase production by Streptomyces sp. ANU 6277. Brazilian Journal of Microbiology, 40(4):725-733.

Pelczar, M. J., \& Chan, E. C. S. (1986). Elements of microbiology. In R.S. Hadioetomo, I. Teja, A.S. Lestari, dan T.S. Sutarmi (alih bahasa), Dasardasar mikrobiologi ( $1^{\text {st }}$ ed.). Jakarta: Universitas Indonesia Press.

Plackett, R. L., \& Burman, J. P. (1946). The design of optimum multifactorial experiments. Biometrika, 33(4):305-325.

Pramesti, E., \& Puspita, I. D. (2020). Optimization of colloidal chitin and inoculum concentration in chitinase production by Streptomyces sp. PB2 using Response Surface Methodology. E3S Web of Conferences, 147(4):03011.

Ray, L. (2018). Purification and characterization of an extracellular thermo-alkali stable, metal tolerant chitinase from Streptomyces chilikensis RC1830 isolated from a brackish water lake sediment. Biotechnology Reports, 21:e00311.

Reissig, J. L., Strominger, J. L., \& Leloir L. F. (1955). A modified colorimetric method for the estimation of N-Acetylamino sugars. Journal of Biological Chemistry, 217(2):959-966.
Romero-Rodríguez, A., Rocha, D., Ruiz-Villafán, B., Guzmán-Trampe, S., Maldonado-Carmona, N., Vázquez-Hernández, M., Zelarayán, A., Rodríguez-Sanoja, R., \& Sánchez, S. (2017). Carbon catabolite regulation in Streptomyces: new insights and lessons learned. World Journal of Microbiology and Biotechnology, 33(9):1-11.

Saima, Kuddus, M., Roohi, \& Ahmad, I. (2013). Isolation of novel chitinolytic bacteria and production optimization of extracellular chitinase. Journal of Genetic Engineering and Biotechnology, 11(1):39-46.

Sanchez, S., \& Demain, A. L. (2008). Metabolic regulation and overproduction of primary metabolites. Microbial Biotechnology, 1(4):283319.

Shivalee, A., Lingappa, K., \& Mahesh, D. (2018). Influence of bioprocess variables on the production of extracellular chitinase under submerged fermentation by Streptomyces pratensis strain KLSL55. Journal of Genetic Engineering and Biotechnology, 16(2):421-426.

Sukalkar, S. R., Kadam, T. A., \& Bhosale, H. J. (2018). Optimization of chitinase production from Streptomyces macrosporeus M1.ResearchJournal of Life Science, Bioinformatics, Pharmaceutical, and Chemical Sciences, 4(1):106-114.

Tarafdar, A., \& Biswas, G. (2013). Extraction of chitosan from prawn shell wastes and examination of its viable commercial applications. International Journal of Theoritical and Applied Research in Mechanical Engineering, 2(3):17-24.

Thiagarajan, V., Revathi, R., Aparanjini, K., Sivamani, P., Girilal, M., Priya, C. S., \& Kalaichelvan, P. T. (2011). Extra cellular chitinase production by Streptomyces sp. PTK19 in submerged fermentation and its lytic activity on Fusarium oxysporum PTK2 cell wall. International Journal of Current Science, 1:30-44.

Tork, S. E., Aly, M. M., \& Elsemin, O. (2018). A new L-glutaminase from Streptomyces pratensis NRC 10: Gene identification, enzyme purification, and characterization. International Journal of Biological Macromolecules, 113:550-557.

Triwijayani, A. U., Puspita, I. D., Murwantoko, \& Ustadi. (2018). Identification of chitinolytic bacteria isolated from shrimp pond sediment and characterization of their chitinase encoding gene. IOP Conference Series: Earth and Environmental 
JIPK. Volume 14 No 1. April 2022 / Optimization of Medium Composition for Streptomyces sp. PB2 Chitinase...

Science, 139:012051.

Tuntun, M., \& Huda, M. (2014). Isolasi dan identifikasi bakteri termofilik dari sumber air panas Way Panas Bumi Natar Lampung Selatan. Jurnal Analis Kesehatan, 3(1):297-304.

Vinuselvi, P., Kim, M. K., Lee, S. K., \& Ghim, C. M. (2012). Rewiring carbon catabolite repression for microbial cell factory. Biochemistry and Molecular Biology Reports, 45(2):59-70.

Wang, Z. Z., Xu, T., Yuan, S. S., Liao, H. D., Yang, Y. Z., Zheng, X. D., Li, Y., Hu, X. C., Liu, Q., Zeng, J. R., Zhu, Y. H., \& Liu, X. M. (2016). Identification of an endophytic actinomyces OsiRt-1 isolated from rice and its effect against rice blast disease. Microbiology China, 43(5):1009-1018.

Xia, J. L., Xiong, J., Zhang, R. Y., Liu, K. K., Huang, B., \& Nie, Z.-Y. (2011). Production of chitinase and its optimization from a novel isolate Serratia marcescens XJ-01. Indian Journal of Microbiology, 51(3):301-306.

Yahiaoui, M., Laribi-Habchi, H., Bouacem, K., Asmani, K.-L., Mechri, S., Harir, M., Bendif, H., AïssaniEl Fertas, R., \& Jaouadi, B. (2019). Purification and biochemical characterization of a new organic solvent-tolerant chitinase from Paenibacillus timonensis strain LK-DZ15 isolated from the Djurdjura Mountains in Kabylia, Algeria. Carbohydrate Research, 483:107747. 